\title{
WISC-IV Intellectual Profiles in Korean Children and Adolescents with Attention Deficit/Hyperactivity Disorder
}

\author{
Yangsik Kim, Min Kyung Koh, Kee Jeong Park, Hyun-Jeong Lee, Go Eun Yu, and Hyo-Won Kim $\bowtie$ \\ Department of Psychiatry, Asan Medical Center, University of Ulsan College of Medicine, Seoul, Republic of Korea
}

\begin{abstract}
Objective This study aimed to compare the Wechsler Intelligence Scale for Children, Fourth Edition (WISC-IV) profiles of children with attention deficit/hyperactivity disorder (ADHD) and typically-developing children (TC) in Korea.

Methods The Korean version of the WISC-IV and the Advanced Test of Attention (ATA) were administered to 377 children and adolescents: 224 with ADHD (age $8.2 \pm 2.1$ years, 182 boys) and 153 TC (age $8.7 \pm 2.4$ years, 68 boys). Partial correlation and an analysis of covariance were used to investigate the relationship between the scores of the WISC-IV and the ATA.

Results The mean score of the full-scale intelligence quotient was lower in ADHD children than in TC ( $\mathrm{p}<0.001)$. In analyses controlling for gender and with the full-scale intelligence quotient as a covariate, the working memory index (WMI) $(\mathrm{p}<0.001)$ and values of the Digit span subtest $(\mathrm{p}=0.001)$ of the WISC-IV were lower in the ADHD group than in TC. The WMI $(r=-0.26, p<0.001)$ and its subtest Arithmetic scores $(\mathrm{r}=-0.25, \mathrm{p}<0.001)$ were negatively correlated with Commission errors on the auditory ATA.

Conclusion Children with ADHD have significantly lower WMI scores, which were clinically correlated with Commission errors on the auditory task of the ATA. Thus, the WMI is an indicator of attention deficit in children with ADHD.
\end{abstract}

Psychiatry Investig 2020;17(5):444-451

Key Words Attention-deficit/hyperactivity disorder, Youth, Intelligence quotient,

Wechsler Intelligence Scale for Children Fourth Edition, Continuous performance test, Working memory index.

\section{INTRODUCTION}

Attention deficit/hyperactivity disorder (ADHD) is one of the most common psychiatric conditions of children and adolescent, which has a prevalence of $5 \%$ to $8 \% .{ }^{1}$ Children with $\mathrm{ADHD}$ are more frequently to experience learning, communication, and intellectual disabilities, and display tic, oppositional defiant, and conduct disorders. ${ }^{2}$ As such, ADHD is related with poor academic performance as well as impaired peer relationships. ${ }^{3-5}$ Because early intervention can mitigate these functional deficits as well as the development of comorbid psychiatric conditions, early diagnosis and treatment of ADHD is crucial. ${ }^{6,7}$

\footnotetext{
Received: November 24, 2019 Revised: February 23, 2020

Accepted: February 28, 2020

$\bowtie$ Correspondence: Hyo-Won Kim, MD, PhD

Department of Psychiatry, Asan Medical Center, University of Ulsan College of Medicine, 88 Olympic-ro 43-gil, Songpa-gu, Seoul 05505, Republic of Korea Tel: +82-2-3010-3414, Fax: +82-2-485-8381, E-mail: shingubi@amc.seoul.kr (a) This is an Open Access article distributed under the terms of the Creative Commons Attribution Non-Commercial License (https://creativecommons.org/licenses/bync/4.0) which permits unrestricted non-commercial use, distribution, and reproduction in any medium, provided the original work is properly cited.
}

Although there are no objective diagnostic tests for ADHD, intelligence tests, including the Wechsler Intelligence Scale for Children (WISC), are widely used to evaluate the cognitive function in children with ADHD. Children with ADHD demonstrate lower intellectual ability than typically-developing children (TC). A meta-analysis showed that the average full-scale intelligent quotient (FSIQ) in children with ADHD is $7-10$ points below the mean of the comparison group. ${ }^{8,9} \mathrm{In}$ addition, FSIQ and four index scores of the WISC can indicate the severity of a variety of impairments in children with ADHD. ${ }^{10}$ However, these scores can reflect general cognitive deficits in other conditions, such as intellectual disabilities or borderline intellectual functioning. Thus, the diagnostic value of the WISC in ADHD remains undetermined.

The fourth edition of the WISC (WISC-IV; 2003) incorporates the expanded understanding of development and cognitive neuroscience since the publication of the WISC-III (1991). ${ }^{11,12}$ The subtests and structure of indices substantially differ from the WISC-III to WISC-IV. First, scores of performance and verbal IQ were replaced with scores of four indices: the Verbal comprehension index (VCI), the Perceptual reasoning index 
(PRI), the Working memory index (WMI), and the Processing speed index (PSI). Although the WISC-IV retains three of the four of verbal IQ subtests from the WISC-III, the PRI has changed substantially and comprises three subtests: two visual reasoning tests with untimed, motor-free manner (Picture concepts and Matrix reasoning), as well as Block design (from the WISC-III). These changes decrease demands on motor/perceptual abilities, providing a more exclusive measure of fluid reasoning. ${ }^{13}$ The WMI comprises the Letter-number sequencing subtest, which more effectively measure the ability to focus the attention and maintain the concentration, and the Digit span (forward and backward) subtest. Lastly, the PSI more clearly measures speed of information processing.

Previous study identified $89 \%$ of children with ADHD from TC via assessments of Digit span, Information, Vocabulary, and Picture completion using the WISC-III. ${ }^{14}$ Another study used Arithmetic, Coding, Symbol search, and Digit span in 'the Freedom from distractibility index', in which the four lowest mean subtest scores were observed in children with ADHD. ${ }^{15}$ However, a study using 'the general abilities index' and 'cognitive proficiency index' in the WISC-IV showed low accuracy in discriminating between ADHD children and TC. ${ }^{16}$

To better assess the diagnostic value of the WISC-IV for children with ADHD, we used the Korean version of the WISC-IV (K-WISC-IV), standardized and released in 2011, to compare Korean ADHD children with TC. We also investigated the correlation between indices and scales of the WISC-IV and the scores of the computerized continuous performance test (CPT) to investigate what elements of the WISC-IV reflect core attentional deficits of ADHD.

\section{METHODS}

\section{Subjects}

Subjects with ADHD were prospectively enrolled from September 2012 to May 2018 on the Department of Pediatric Psychiatry of Asan Medical Center, located in Seoul, South Korea. To include of the study, ADHD subjects had to be from 6 to 12 year-old age and diagnosed ADHD according to the Diagnostic and Statistical Manual of Mental Disorders, Fourth Edition, Text Revision (DSM-IV-TR) and the Kiddie Schedule Affective Disorders and Schizophrenia for School-Age Children-Present and Lifetime version (K-SADS-PL), whereas TC subjects had to be from 6 to 12 years of age and not ever meet the criteria for a diagnosis of ADHD. TC subjects were recruited by advertisements on the staff board at Asan Medical Center.

Participants were excluded from this study when they had any of the following exclusion criteria: 1) IQ score lower than 70 according to the K-WISC-IV, 2) any history of schizophre- nia, organic mental disorder, and pervasive developmental disorder 3) any history of other neurological disorders including seizure, 4) presence of impairments in any sensorium, and 5) lifetime history of taking stimulants or atomoxetine more than 3 months or history of taking any psychotropic drug within the last 6 months.

The study received ethical approval from the Institutional Review Board in Asan Medical Center (2012-0767). Informed consent was obtained from the parents of all children included in the study, and assent/consent was obtained from all children.

\section{Assessment and measures}

$\mathrm{ADHD}$ and other psychiatric comorbidities of both ADHD and TC subjects were diagnosed by certified child and adolescent psychiatrists (H.W.K., H.J.L., and K.J.P.), and psychiatric diagnosis of these conditions were also confirmed by K-SADS$\mathrm{PL} ;{ }^{17,18}$ one of the fifth of the K-SADS-PL scores were rated independently by three individuals to ensure consistency in evaluations. Discrepancies were resolved through consensus (kappa coefficients: 0.76 to 0.90 ).

The K-WISC-IV, standardized by Kwak et al., ${ }^{19}$ is an assessment for children and adolescents from 6 years to 16 years 11 months of age and comprises four indices (VCI, PRI, WMI, and PSI). Standardized scores for these indices were used along with FSIQ score, which were transformed from raw scores to scaled scores. The scaled scores were adjusted for age for each variable, including Similarities, Vocabulary, Comprehension, Block design, Picture concepts, Matrix reasoning, Picture completion, Digit span, Digit span forward, Digit span backward, Arithmetic, Coding, and Symbol search.

The Advanced Test of Attention (ATA) is a type of computerized continuous performance test developed and standardized in South Korea, ${ }^{20}$ which is used to measure attention and impulsivity. The four major variables recorded are 1) Omission errors (for inattentiveness), 2) Commission errors (for impulsivity), 3) Response time (for task performance speed), and 4) the standard deviations of the response times for correct responses (Response time variability; for the consistency of attention). In addition, the Korean version of the ADHD Rating Scale was used for assessing the severity of ADHD symptoms in children as reported by parents and teachers. ${ }^{21}$

\section{Statistical analysis}

Statistical analyses were performed using $\mathrm{R}$ (3.5.1) with $\mathrm{R}$ studio (1.0.153). The normality of data was assessed by Shapiro-Wilk tests. Results from the ADHD group and TC were compared with chi-square tests, Fisher's exact tests, Student's t-tests, and analyses of covariance, adjusted for FSIQ and gender. Partial correlation analyses were used to determine the 
relationship among the scores of WISC-IV indices and subtests and ATA scores, adjusted for FSIQ and gender.

\section{RESULTS}

\section{Subject characteristics}

The characteristics of children with ADHD and TC are presented in Table 1 . There were no differences between the groups regarding age $(\mathrm{p}=0.104)$, but there were more boys in the ADHD group than in the TC group ( $\mathrm{p}<0.001)$. The majority of children with ADHD were classified as having the inattentive and combined subtypes. Oppositional defiant disorder $(\mathrm{p}<0.001)$ and tic disorder $(\mathrm{p}=0.022)$ were significantly more frequent in the ADHD than in the TC group. The groups did not differ with regard to other comorbid psychiatric disorders.

\section{Differences in K-WISC-IV and ATA scores between groups}

The mean FSIQ was significantly lower in the ADHD than in the TC group $(\mathrm{p}<0.001)$ (Table 2$)$. Thus, FSIQ and gender were controlled as covariates in analyses of covariance. Among the index scores of the K-WISC-IV, only WMI $(\mathrm{p}<0.001)$ score was significantly lower in the ADHD than in the TC group after adjusting for FSIQ and gender and controlling for multi-

Table 1. Demographic and clinical characteristics of ADHD and TC subjects

\begin{tabular}{|c|c|c|c|c|}
\hline Characteristic & $\begin{array}{l}\text { ADHD } \\
(\mathrm{N}=224)\end{array}$ & $\begin{array}{c}\mathrm{TC} \\
(\mathrm{N}=153)\end{array}$ & tor $\chi^{2} 1$ & p-value \\
\hline Age, years, mean (SD) & $8.2(2.1)$ & $8.7(2.4)$ & 1.83 & 0.104 \\
\hline \multicolumn{5}{|l|}{ Gender } \\
\hline Boys, N (\%) & $182(81.3)$ & $68(44.4)$ & 55.10 & $<0.001$ \\
\hline \multicolumn{5}{|l|}{ Subtype, N (\%) } \\
\hline Inattentive & $107(47.8)$ & & & \\
\hline Hyperactive/impulsive & $9(4.0)$ & & & \\
\hline Combined & $95(42.4)$ & & & \\
\hline NOS & $13(5.8)$ & & & \\
\hline Comorbid diagnosis, N (\%) & $60(26.8)$ & $16(10.4)$ & & \\
\hline ODD* & $25(11.2)$ & - & 18.30 & $<0.001$ \\
\hline $\mathrm{MDD}^{*}$ & $3(1.3)$ & $2(1.3)$ & 0.00 & 0.979 \\
\hline Anxiety disorder & $13(5.8)$ & $10(6.5)$ & 0.09 & 0.770 \\
\hline Enuresis* & $2(0.9)$ & - & 1.37 & 0.240 \\
\hline Tic disorder & $21(9.4)$ & $5(3.2)$ & 5.28 & 0.022 \\
\hline \multicolumn{5}{|l|}{ ARS, mean (SD) } \\
\hline Inattentive & $29.1(44.0)$ & $13.2(41.0)$ & -17.4 & $<0.001$ \\
\hline Hyperactive/impulsive & $29.6(38.9)$ & $11.9(24.4)$ & -14.8 & $<0.001$ \\
\hline
\end{tabular}

ple comparison. PRI ( $\mathrm{p}=0.030)$ score was decreased compared to TC, but this difference was disappeared with multiple comparison correction. Among the subtests of these indices, only a score for Digit span ( $\mathrm{p}=0.001)$ within the WMI were significantly lower in the ADHD group after controlling for FSIQ and gender and adjusting for multiple comparison. Similarities $(\mathrm{p}=0.043)$, Picture concepts $(\mathrm{p}=0.024)$ and Matrix reasoning $(\mathrm{p}=0.030)$ were decreased compared to TC, but this difference was disappeared when adjusted for multiple comparison. For the ATA, after correcting for multiple comparison, only the increase in Omission errors for the auditory task $(\mathrm{p}<0.001)$ in the ADHD group remained significant. Response time for the visual task $(\mathrm{p}=0.031)$ were also significantly higher in ADHD group than TC, but this significance was disappeared after multiple comparison corrected.

We further dissected the difference between the groups for the Digit span subtest within the WMI of the K-WISC-IV. The mean scores for Digit span forward $(\mathrm{p}=0.041)$ and backward $(\mathrm{p}=0.114)$ did not differ between the ADHD and TC groups after controlling for FSIQ and gender and correcting for multiple comparisons (Table 3).

\section{Associations among scores of the K-WISC-IV, ATA, and $A D H D$ rating scale}

To investigate which factor of the K-WISC-IV would be affected by the attentional abilities of the ADHD group according to the ATA, we performed partial correlation analyses with adjustments for FSIQ and gender. Only WMI showed a meaningful negative correlation $(|\mathrm{r}|>0.2)$ with Commission errors on the auditory tasks of the ATA $(\mathrm{r}=-0.26, \mathrm{p}<0.001)$ (Table 4). Various subtests of K-WISC-IV correlated significantly, but only the Arithmetic subtest $(r=-0.25, p<0.001)$ of the WMI index showed a meaningful negative correlation (Table 5).

\section{DISCUSSION}

In our study, children with ADHD showed lower scores for the FSIQ, WMI, and Digit span subtests of the K-WISC-IV. In addition, the WMI score and Arithmetic subtest score of the WISC-IV correlated negatively with Commission errors on the auditory task of the ATA. In our previous retrospective chart review, we reported that children with ADHD showed low average scores in WMI and PSI which were clinically correlated with ATA scores ${ }^{22}$ and hypothesized that WISC-IV profile, especially the WMI could play an important role in diagnosing $\mathrm{ADHD}$. This prospective comparison of children with ADHD and TC confirmed our hypothesis and suggest that the WISC-IV can be used to measure attention deficits in children with ADHD.

Our results are consistent with several previous findings 
showing that children ${ }^{11,23-30}$ and adults ${ }^{31}$ with ADHD consistently have lower FSIQ scores, which moderately correlate not only with ADHD symptoms ${ }^{32-34}$ but also with functional outcomes. ${ }^{35,36}$ We and other researchers have found that lower FSIQ scores of WISC-III and WISC-IV in children with ADHD are attributable to deficits in PSI and WMI rather than in VCI and PRI. ${ }^{22,37,38}$ Here, we show that WMI scores are significantly lower in ADHD children when adjusting for FSIQ and gender, demonstrating that the WMI as well as FSIQ can be used as measures of ADHD. Lower WMI scores in children with ADHD are associated with decreased behavioral function. ${ }^{35,39}$ Indeed, a working memory impairment is a core neuropsychological deficit in subjects with ADHD and is proposed as an endophenotype of ADHD. ${ }^{40-42}$ Working memory deficits involve "cool" executive function, comprising motor response inhibition, sustained attention, response variability, and cognitive switching as well as working memory, and are consistently reported in clinical and cognitive neuroscience studies

Table 3. The K-WISC-IV Digit span scores of ADHD and TC

\begin{tabular}{|c|c|c|c|c|}
\hline \multirow{2}{*}{ Digit span } & \multicolumn{2}{|c|}{ Mean (SD) score } & \multirow{2}{*}{ p-value } & \multirow{2}{*}{$\begin{array}{l}\text { Adjustec } \\
\text { p-value* }\end{array}$} \\
\hline & $\operatorname{ADHD}(\mathrm{N}=179)$ & $\mathrm{TC}(\mathrm{N}=132)$ & & \\
\hline Forward & $10.0(3.6)$ & $11.9(2.8)$ & $<0.001$ & 0.041 \\
\hline Backward & $9.0(3.6)$ & $10.6(3.1)$ & $<0.001$ & 0.114 \\
\hline
\end{tabular}

Multiple comparison corrected significance level, $\mathrm{p}<0.025 .{ }^{*}$ adjusted for FSIQ and gender. ADHD: attention deficit/hyperactivity disorder, K-WISC-IV: Korean-Wechsler Intelligence Scale for Children, Fourth Edition, TC: typically-developing children, FSIQ: full-scale intelligent quotient

Table 2. The K-WISC-IV and ATA scores of ADHD and TC subjects

\begin{tabular}{|c|c|c|c|c|c|c|c|}
\hline \multirow{2}{*}{ Assessment } & \multicolumn{2}{|c|}{$\mathrm{ADHD}$} & \multicolumn{2}{|r|}{ TC } & \multirow{2}{*}{$\operatorname{tor} \chi^{2}$} & \multirow{2}{*}{$\mathrm{p}$-value } & \multirow{2}{*}{$\begin{array}{l}\text { Adjustec } \\
\text { p-value* }\end{array}$} \\
\hline & $\mathrm{N}$ & Mean (SD) & $\mathrm{N}$ & Mean (SD) & & & \\
\hline FSIQ & & $95.4(15.0)$ & & $106.0(13.6)$ & 7.04 & $<0.001$ & - \\
\hline VCI & & $98.4(12.9)$ & & $103.7(15.0)$ & 3.65 & $<0.001$ & 0.121 \\
\hline Similarities & 218 & $9.4(2.0)$ & 152 & $10.6(2.7)$ & 3.86 & $<0.001$ & 0.043 \\
\hline Vocabulary & 218 & $10.6(2.7)$ & 152 & $11.2(3.2)$ & 1.97 & 0.05 & 0.113 \\
\hline Comprehension & 218 & $9.0(2.6)$ & 152 & $9.9(2.9)$ & 3.06 & 0.001 & 0.856 \\
\hline PRI & & $99.9(16.2)$ & & $107.9(15.9)$ & 4.78 & $<0.001$ & 0.012 \\
\hline Block design & 218 & $10.5(3.0)$ & 152 & 115. (3.1) & 3.08 & 0.008 & 0.356 \\
\hline Picture concepts & 176 & $9.4(3.2)$ & 151 & $10.5(3.2)$ & 3.22 & 0.003 & 0.024 \\
\hline Matrix reasoning & 217 & $9.8(3.0)$ & 152 & $11.3(2.9)$ & 4.75 & $<0.001$ & 0.030 \\
\hline Picture completion & 146 & $9.3(2.6)$ & 78 & $10.3(2.6)$ & 2.53 & $<0.001$ & 0.057 \\
\hline WMI & & $96.1(16.5)$ & & $107.8(13.6)$ & 7.2 & $<0.001$ & $<0.001$ \\
\hline Digit span & 218 & $9.5(3.5)$ & 152 & $11.8(2.8)$ & 6.65 & 0.003 & 0.001 \\
\hline Arithmetic & 164 & $9.1(3.1)$ & 120 & $11.1(2.9)$ & 5.55 & $<0.001$ & 0.114 \\
\hline PSI & & $91.3(14.7)$ & & $99.2(14.3)$ & 5.14 & $<0.001$ & 0.111 \\
\hline Coding & 218 & $8.3(3.2)$ & 152 & $9.5(2.9)$ & 3.44 & $<0.001$ & 0.496 \\
\hline Symbol search & 218 & $8.7(2.8)$ & 152 & $10.2(2.9)$ & 5.02 & $<0.001$ & 0.729 \\
\hline \multicolumn{8}{|l|}{ ATA visual } \\
\hline Omission errors & & $29.1(44.0)$ & & $13.2(41.0)$ & -3.57 & $<0.001$ & 0.255 \\
\hline Commission errors & & $29.6(38.9)$ & & $11.9(24.4)$ & -4.96 & $<0.001$ & 0.883 \\
\hline Response time & & $7.8(15.3)$ & & $6.1(11.0)$ & -1.33 & 0.64 & 0.031 \\
\hline Response time variability & & $19.9(27.5)$ & & $8.0(25.7)$ & -4.32 & $<0.001$ & 0.359 \\
\hline \multicolumn{8}{|l|}{ ATA auditory } \\
\hline Omission errors & & $12.8(24.7)$ & & $7.7(22.0)$ & -2.07 & $<0.001$ & 0.001 \\
\hline Commission errors & & $14.7(24.8)$ & & $5.6(17.6)$ & -3.93 & $<0.001$ & 0.080 \\
\hline Response time & & $-3.2(12.5)$ & & $0.4(8.0)$ & 3.08 & 0.034 & 0.543 \\
\hline Response time variability & & $0.04(11.1)$ & & $-3.2(9.0)$ & -2.93 & 0.005 & 0.149 \\
\hline
\end{tabular}

Multiple comparison corrected significance level $\mathrm{p}<0.002 .{ }^{*}$ adjusted for FSIQ and gender. Different number of subtests of K-WISC-IV due to children's developmental stages. ATA: Advanced Test of Attention, K-WISC-IV: Korean-Wechsler Intelligence Scale for Children, Fourth Edition, FSIQ: full-scale intelligent quotient, VCI: verbal comprehension index, PRI: perceptual reasoning index, WMI: working memory index, PSI: processing speed index, TC: typically-developing children 
of children with ADHD. ${ }^{43-45}$ Working memory utilizes the inferior fronto-striatal circuit in the brain and is described as a limited-capacity system to manipulate cognitive representations from stimuli, to search for similar or same stimuli in previous experiences, and also to maintain responses. ${ }^{46}$ Thus, working memory deficits reflect the core attention deficit of ADHD children and, as demonstrated here, can be assessed via the WMI of the WISC-IV.

We also found that WMI scores negatively correlated with scores of Commission errors on the auditory ATA but not with Omission errors. Although both types of errors are associated with inattention, hyperactivity, and impulsivity, Commission

Table 4. Partial correlation analyses among four indexes of $\mathrm{K}$ WISC-IV and ATA, adjusted for FSIQ and gender

\begin{tabular}{lcccc}
\hline \multicolumn{1}{c}{ Assessment } & VCI & PRI & WMI & PSI \\
\hline ATA visual & & & & \\
$\quad$ Omission errors & 0.09 & 0.02 & $-0.11^{*}$ & -0.02 \\
Commission errors & 0.07 & -0.65 & -0.04 & 0.02 \\
Response time & 0.10 & 0.06 & 0.03 & $-0.20^{* * *}$ \\
$\quad$ Response time variability & $0.11^{*}$ & -0.04 & $<0.01$ & -0.09 \\
ATA auditory & & & & \\
Omission errors & $<0.001$ & 0.75 & $-0.12^{*}$ & $<0.01$ \\
Commission errors & $0.17^{* *}$ & -0.01 & $-0.26^{* * *}$ & 0.03 \\
Response time & -0.10 & 0.58 & $0.14^{* *}$ & -0.07 \\
Response time variability & 0.03 & 0.04 & -0.10 & 0.02 \\
\hline
\end{tabular}

${ }^{*} \mathrm{p}<0.05,{ }^{* *} \mathrm{p}<0.01,{ }^{* * *} \mathrm{p}<0.001$. ATA: Advanced Test of Attention, K-WISC-IV: Korean-Wechsler Intelligence Scale for Children, Fourth Edition, VCI: verbal comprehension index, PRI: perceptual reasoning index, WMI: working memory index, PSI: processing speed index, FSIQ: full-scale intelligent quotient errors is considered to measure response inhibition whereas Omission errors measure selective attention. ${ }^{47,48}$ However, the relationship between response inhibition and working memory is complex. Our results are consistent with Raiker et al.s ${ }^{49}$ study which reported that working memory is associated with ADHD-related impulsivity. By contrast, Chhabildas et al..$^{50} \mathrm{did}$ not observe a response inhibition deficit in individuals who have the hyperactive-impulsive subtype of ADHD and suggested that inattentive symptoms, rather than hyperactivity/ impulsivity symptoms, are a core neuro-psychological impairment of ADHD. Nevertheless, a meta-analysis indicated that response inhibition is one of the strongest and most consistent factors contributing to executive function in $\mathrm{ADHD}$ regardless of subtype. ${ }^{51}$ Thus, further study is needed to determine the association between working memory and response inhibition in children with ADHD.

Among the subtests included in the WMI, the score for the Digit span subtest were decreased in children with ADHD compared with TC, consistent with a previous study, ${ }^{52}$ but the score for the Arithmetic subtest was not. Digit span and Arithmetic subtests, along with the Coding and Symbol search subtest of the WISC-III, were used to measure working memory in a study by Fried et al. ${ }^{39}$ as Freedom from distractibility factor scores, which are more decreased for children with ADHD than for TC. ${ }^{53,54}$ Rosenthal et al. ${ }^{55}$ also reported lower Digit span scores for individuals with ADHD than for TC, but the difference was not significant after controlling for general cognitive ability. Scores for the Digit span backward, a measure of central executive system in the putative working memory model, ${ }^{11}$ are lower for children with ADHD than in TC, particularly in those with an inattentive type of $\mathrm{ADHD},{ }^{56}$ but this

Table 5. Partial correlation analyses among 14 subtests of K-WISC-IV and ATA adjusted for FSIQ and gender

\begin{tabular}{|c|c|c|c|c|c|c|c|c|}
\hline \multirow{2}{*}{$\begin{array}{c}\text { K-WISC-IV } \\
\text { subtests }\end{array}$} & \multicolumn{4}{|c|}{ ATA visual } & \multicolumn{4}{|c|}{ ATA auditory } \\
\hline & $\begin{array}{c}\text { Omission } \\
\text { errors }\end{array}$ & $\begin{array}{c}\text { Commission } \\
\text { errors }\end{array}$ & $\begin{array}{l}\text { Response } \\
\text { time }\end{array}$ & $\begin{array}{c}\text { Response time } \\
\text { variability }\end{array}$ & $\begin{array}{c}\text { Omission } \\
\text { errors }\end{array}$ & $\begin{array}{c}\text { Commission } \\
\text { errors }\end{array}$ & $\begin{array}{c}\text { Response } \\
\text { time }\end{array}$ & $\begin{array}{c}\text { Response time } \\
\text { variability }\end{array}$ \\
\hline Similarities & 0.04 & -0.02 & $0.12^{*}$ & 0.02 & 0.05 & 0.03 & 0.02 & 0.03 \\
\hline Vocabulary & $0.11^{*}$ & $0.11^{*}$ & 0.05 & $0.12^{*}$ & -0.44 & $0.11^{*}$ & -0.08 & 0.03 \\
\hline Comprehension & 0.002 & 0.03 & 0.03 & 0.06 & 0.01 & $0.16^{* *}$ & $-0.13^{*}$ & 0.01 \\
\hline Block design & 0.09 & 0.04 & 0.04 & 0.001 & 0.07 & 0.005 & -0.02 & 0.10 \\
\hline Picture concepts & -0.02 & -0.06 & 0.08 & -0.01 & 0.01 & 0.006 & 0.06 & 0.10 \\
\hline Matrix reasoning & -0.09 & $-0.13^{*}$ & -0.04 & -0.10 & 0.07 & -0.09 & $0.11^{*}$ & $-0.15^{* *}$ \\
\hline Picture completion & 0.001 & 0.003 & -0.04 & 0.06 & -0.12 & 0.08 & -0.04 & -0.05 \\
\hline Digit span & -0.06 & -0.02 & 0.02 & -0.02 & -0.09 & $-0.14^{* *}$ & 0.10 & -0.07 \\
\hline Arithmetic & -0.11 & 0.02 & 0.03 & 0.07 & -0.09 & $-0.25^{* * *}$ & 0.08 & -0.38 \\
\hline Coding & -0.02 & 0.07 & $-0.15^{* *}$ & -0.04 & 0.003 & 0.004 & -0.09 & 0.06 \\
\hline Symbol search & -0.02 & -0.06 & $-0.18^{* * *}$ & $-0.11^{*}$ & 0.001 & 0.05 & -0.01 & -0.02 \\
\hline
\end{tabular}

${ }^{*} \mathrm{p}<0.05,{ }^{* *} \mathrm{p}<0.01,{ }^{* * *} \mathrm{p}<0.001$. ADHD: attention deficit/hyperactivity disorder, ATA: Advanced Test of Attention, K-WISC-IV: KoreanWechsler Intelligence Scale for Children, Fourth Edition, FSIQ: full-scale intelligent quotient 
is not consistently reported across the subtypes of ADHD. ${ }^{51,55}$ We previously found that scores for the Digit span backward and auditory tasks of the ATA are correlated in children with $\mathrm{ADHD} .{ }^{22}$ But this correlation was not observed in the present study using TC as a control group. In addition, another study performed in South Korea showed decreased Digit span score compared to verbal IQ index measured by K-WISC-III. ${ }^{57}$ Overall, the Digit span subtest of the WMI predicts the attention ability of children with ADHD, but more studies are needed to investigate whether Digit span forward and backward scores represent attention abilities in children with ADHD.

Several limitations should be considered when interpreting our results. First, ADHD is more prevalent in boys, and a gender difference was expected and can be a marker of a reliable and representative cohort. ${ }^{58}$ Second, this study focused mainly on the relationship between the WISC-IV and ATA; thus, the functional abilities of ADHD children were not included. Furthermore, this study was carried out in a hospital setting and thus may not generalize to other populations. Finally, the data presented here show associations and not causal relationships. Despite these limitations, there were strengths in this study. First, the number of subjects enrolled in this study were sufficient to detect an effect of tasks. Second, diagnosis of ADHD and comorbid psychiatric disorders are based on the K-SADS-PL which is a semi-structured interview conducted by experienced pediatric psychiatrist. Third, the tasks used to measure cognitive function and attention were comprehensive and could complement each other. Fourth, this was a prospective case-control study comparing ADHD children with TC. Finally, all study participants were not taking any psychotropic medication. Because stimulant is known to improve FSIQ and all indexes of WISC-IV, including only drug-naïve subject is important to assessing WISC-IV profile of ADHD. About 70\% of children newly diagnosed ADHD take stimulants in South Korea, and children with ADHD who receive stimulants showed increased FSIQ and all of indexes of WISC-IV. ${ }^{59-62}$

In summary, we investigated the demographic and cognitive characteristics of children with ADHD using the K-WISCIV, ADHD Rating Scale, and ATA. The results of this study show that working memory is impaired in children with $\mathrm{ADHD}$ and can be assessed with the WMI of the WISC-IV.

\section{Acknowledgments}

This work was supported by a National Research Foundation of Korea (NRF) grant (no. 2018R1A2B6002216) funded by the Korean Government (Ministry of Science and ICT).

\section{Conflicts of Interest}

The authors have no potential conflicts of interest to disclose.

\section{Author Contributions}

Conceptualization: Hyo-Won Kim, Min Kyung Koh. Data curation: Go Eun Yu, Yangsik Kim, Kee Jeong Park, Hyun-Jeong Lee. Formal analysis: Yangsik Kim, Hyo-Won Kim. Funding acquisition: Hyo-Won Kim. Investigation: Min Kyung Koh, Kee Jeong Park, Hyun-Jeong Lee, Go Eun Yu, Hyo-Won Kim. Methodology: Yangsik Kim, Hyo-Won Kim. Project administration: Hyo-Won Kim. Resource: Min Kyung Koh, Kee Jeong Park, Hyun-Jeong Lee, Go Eun Yu, Hyo-Won Kim. Supervision: Hyo-Won Kim. Validation: Hyo-Won Kim. Visualization: Yangsik Kim, Hyo-Won Kim. Writing-original draft: Yangsik Kim, Hyo-Won Kim. Writing—review \& editing: Yangsik Kim, Hyo-Won Kim.

\section{ORCID iDs}

Yangsik Kim

Min Kyung Koh

Kee Jeong Park

Hyun-Jeong Lee

Go Eun Yu

Hyo-Won Kim

https://orcid.org/0000-0003-1841-727X

https://orcid.org/0000-0003-4189-6483

https://orcid.org/0000-0002-9709-8723

https://orcid.org/0000-0002-2027-6835

https://orcid.org/0000-0003-1856-8537

https://orcid.org/0000-0002-8744-5138

\section{REFERENCES}

1. Moffitt TE, Houts R, Asherson P, Belsky DW, Corcoran DL, Hammerle $\mathrm{M}$, et al. Is adult ADHD a childhood-onset neurodevelopmental disorder? Evidence from a four-decade longitudinal cohort study. Am J Psychiatry 2015;172:967-977.

2. Rostain A, Jensen PS, Connor DF, Miesle LM, Faraone SV. Toward quality care in ADHD: defining the goals of treatment. J Atten Disord 2015;19:99-117.

3. Barkley RA, Smith KM, Fischer M, Navia B. An examination of the behavioral and neuropsychological correlates of three ADHD candidate gene polymorphisms (DRD4 7+, DBH TaqI A2, and DAT1 40 bp VNTR) in hyperactive and normal children followed to adulthood. Am J Med Genet B Neuropsychiatr Genet 2006;141B:487-498.

4. Faraone SV, Biederman J. ADHD: disorder or discipline problem? Science 2001;291:1488-1489.

5. Marshall SA, Evans SW, Eiraldi RB, Becker SP, Power TJ. Social and academic impairment in youth with $\mathrm{ADHD}$, predominately inattentive type and sluggish cognitive tempo. J Abnorm Child Psychol 2014; 42:77-90.

6. Jones K, Daley D, Hutchings J, Bywater T, Eames C. Efficacy of the Incredible Years Basic parent training programme as an early intervention for children with conduct problems and ADHD. Child Care Health Dev 2007;33:749-756.

7. McGoey KE, Eckert TL, DuPaul GJ. Early intervention for preschoolage children with ADHD: a literature review. J Emot Behav Disord 2002;10:14-28.

8. Barkley RA. Attention-Deficit Hyperactivity Disorder: A Handbook for Diagnosis and Treatment. New York, NY: Guilford Publications; 2014.

9. Frazier TW, Demaree HA, Youngstrom EA. Meta-analysis of intellectual and neuropsychological test performance in attention-deficit/hyperactivity disorder. Neuropsychology 2004;18:543-555.

10. Weiss LG, Saklofske DH, Schwartz DM, Prifitera A, Courville T. Advanced Clinical Interpretation of WISC-IV Index Scores. In: Weiss LG, Saklofske DH, Prifitera A, Holdnack J, Editor. WISC-IV Advanced Clinical Interpretation. Cambridge, MA: Academic Press, 2006, p.140-181.

11. Wechsler D. Wechsler Intelligence Scale for Children-Fourth Edition (WISC-IV). San Antonio, TX: The Psychological Corporation; 2003.

12. Gomez R, Vance A, Watson SD. Structure of the Wechsler Intelligence Scale for Children-Fourth Edition in a group of children with ADHD. Front Psychol 2016;7:737.

13. Kaufman AS, Flanagan DP, Alfonso VC, Mascolo JT. Test review: Wechsler Intelligence Scale for Children (WISC-IV). J Psychoeduc As- 
sess 2006;24:278-295.

14. Assesmany A, McIntosh DE, Phelps L, Rizza MG. Discriminant validity of the WISC-III with children classified with ADHD. J Psychoeduc Assess 2001;19:137-147.

15. Dickerson Mayes S, Calhoun SL, Crowell EW. WISC-III freedom from distractibility as a measure of attention in children with and without attention deficit hyperactivity disorder. J Atten Disord 1998;2:217-227.

16. Devena SE, Sarah E, Watkins MW. Diagnostic utility of WISC-IV general abilities index and cognitive proficiency index difference scores among children with ADHD. J Appl School Psychol 2012;28:133-154.

17. Kaufman J, Birmaher B, Brent D, Rao U, Flynn C, Moreci P, et al. Schedule for affective disorders and schizophrenia for School-Age ChildrenPresent and Lifetime Version (K-SADS-PL): initial reliability and validity data. J Am Acad Child Adolesc Psychiatry 1997;36:980-988.

18. Kim YS, Cheon KA, Kim BN, Chang SA, Yoo HJ, Kim JW, et al. The reliability and validity of Kiddie-Schedule for Affective Disorders and Schizophrenia-Present and Lifetime Version- Korean version (K-SADSPL-K). Yonsei Med J 2004;45:81-89.

19. Kwak KJ, Oh SW, Kim CT. Korean-Wechsler Intelligence Scale for Children. 4th ed. Seoul: Hakjisa; 2011.

20. Shin MS, Cho SC, Chun SY, Hong KE. A study of the development and standardization of ADHD diagnostic system. J Kor Acad Child Adolesc Psychiatry 2000;11:91-99.

21. Park JI, Shim SH, Lee M, Jung YE, Park TW, Park SH, et al. The validities and efficiencies of Korean ADHD rating scale and Korean child behavior checklist for screening children with ADHD in the community. Psychiatry Investig 2014;11:258-265.

22. Mayes SD, Calhoun SL. WISC-IV and WISC-III profiles in children with ADHD. J Atten Disord 2006;9:486-493.

23. Carte ET, Nigg JT, Hinshaw SP. Neuropsychological functioning, motor speed, and language processing in boys with and without ADHD. J Abnorm Child Psychol 1996;24:481-498.

24. Snow JB, Sapp GL. WISC-III subtest patterns of ADHD and normal samples. Psychol Rep 2000;87:759-765.

25. Mariani MA, Barkley RA. Neuropsychological and academic functioning in preschool boys with attention deficit hyperactivity disorder. Dev Neuropsychol1997;13:111-129.

26. Crosbie J, Schachar RJ. Deficient inhibition as a marker for familial ADHD. Am J Psychiatry 2001;158:1884-1890.

27. Rucklidge JJ, Tannock R. Psychiatric, psychosocial, and cognitive functioning of female adolescents with ADHD. J Am Acad Child Adolesc Psychiatry 2001;40:530-540.

28. Fergusson DM, Horwood LJ. Predictive validity of categorically and dimensionally scored measures of disruptive childhood behaviors. J Am Acad Child Adolesc Psychiatry 1995;34:477-487.

29. Rapport MD, Scanlan SW, Denney CB. Attention-deficit/hyperactivity disorder and scholastic achievement: a model of dual developmental pathways. J Child Psychol Psychiatry 1999;40:1169-1183.

30. Theiling J, Petermann F. Neuropsychological profiles on the WAIS-IV of adults with ADHD. J Atten Disord 2016;20:913-924.

31. Rommel AS, Rijsdijk F, Greven CU, Asherson P, Kuntsi J. A longitudinal twin study of the direction of effects between ADHD symptoms and IQ. PLoS One 2015;10:e0124357.

32. Wood AC, Asherson P, van der Meere JJ, Kuntsi J. Separation of genetic influences on attention deficit hyperactivity disorder symptoms and reaction time performance from those on IQ. Psychol Med 2010;40: 1027-1037.

33. Kuntsi J, Eley TC, Taylor A, Hughes C, Asherson P, Caspi A, et al. Cooccurrence of ADHD and low IQ has genetic origins. Am J Med Genet B Neuropsychiatr Genet 2004;124B:41-47.

34. Thaler NS, Bello DT, Etcoff LM. WISC-IV profiles are associated with differences in symptomatology and outcome in children with ADHD. J Attend Disord 2013;17:291-301.

35. Mannuzza S, Klein RG, Abikoff H, Moulton Iii JL. Significance of childhood conduct problems to later development of conduct disorder among children with ADHD: a prospective follow-up study. J Abnorm Child Psychol 2004;32:565-573.

36. Prifitera A, Dersh J. Base Rates of WISC-III Diagnostic Subtest Patterns among Normal, Learning-Disabled, and ADHD Samples. In: Bracken BA, McCallum RS, Editors. Journal of Psychoeducational Assessment Monograph Series. Advances in Psychoeducational Assessment. Wechsler Intelligence Scale for Children. Brandon, VT: Clinical Psychology Publishing Co, 1993, p.43-55.

37. Mayes SD, Calhoun SL. WISC-IV and WISC-III profiles in children with ADHD. J Attend Disord 2006;9:486-493.

38. Koh M, Noh EA, Kim HW. Korean Wechsler Intelligence Scale for children-profiles in child and adolescent with attention-deficit hyperactivity disorder: retrospective study. J Kor Acad Child Adolesc Psychiatry 2015;26:183-189.

39. Fried R, Chan J, Feinberg L, Pope A, Woodworth KY, Faraone SV, et al. Clinical correlates of working memory deficits in youth with and without ADHD: a controlled study. J Clin Exp Neuropsychol. 2016;38: 487-496.

40. Diamond A, Barnett WS, Thomas J, Munro S. Preschool program improves cognitive control. Science 2007;318:1387-1388.

41. Barkley RA. Behavioral inhibition, sustained attention, and executive functions: constructing a unifying theory of ADHD. Psychol Bull 1997; 121:65-94.

42. Zang YF, He Y, Zhu CZ, Cao QJ, Sui MQ, Liang M, et al. Altered baseline brain activity in children with ADHD revealed by resting-state functional MRI. Brain Dev 2007;29:83-91.

43. Willcutt EG, Betjemann RS, McGrath LM, Chhabildas NA, Olson RK, DeFries JC, et al. Etiology and neuropsychology of comorbidity between RD and ADHD: the case for multiple-deficit models. Cortex 2010;46:1345-1361.

44. Rubia K. "Cool” inferior frontostriatal dysfunction in attention-deficit/ hyperactivity disorder versus "hot" ventromedial orbitofrontal-limbic dysfunction in conduct disorder: a review. Biol Psychiatry 2011;69: e69-e87.

45. Rubia K. Cognitive neuroscience of attention deficit hyperactivity disorder (ADHD) and its clinical translation. Front Hum Neurosci 2018; 12:100.

46. Baddeley A. Working memory: looking back and looking forward. Nat Rev Neurosci 2003;4:829-839.

47. Epstein JN, Erkanli A, Conners CK, Klaric J, Costello JE, Angold A. Relations between continuous performance test performance measures and ADHD behaviors. J Abnorm Child Psychol 2003;31:543554.

48. Diamond A. Executive functions. Ann Rev Psychol 2013;64:135-168.

49. Raiker JS, Rapport MD, Kofler MJ, Sarver DE. Objectively-measured impulsivity and attention-deficit/hyperactivity disorder (ADHD): testing competing predictions from the working memory and behavioral inhibition models of ADHD. J Abnorm Child Psychol 2012;40:699713.

50. Chhabildas N, Pennington BF, Willcutt EG. A comparison of the neuropsychological profiles of the DSM-IV subtypes of ADHD. J Abnorm Child Psychol 2001;29:529-540.

51. Lee SI, Lim EJ, Park JH, Jung HY. Comparison of working memory among the subtypes of child and adolescent attention-deficit/hyperactivity disorder. Kor J Biol Psychiatry 2010;17:70-78.

52. Gau SS, Shang CY. Executive functions as endophenotypes in ADHD: evidence from the Cambridge Neuropsychological Test Battery (CANTAB). J Child Psychol Psychiatry 2010;51:838-849.

53. Lufi D, Cohen A, Parish-Plass J. Identifying attention deficit hyperactive disorder with the WISC-R and the stroop color and word test. Psychol Sch 1990;27:28-34.

54. Anastopoulos AD, Spisto MA, Maher MC. The WISC-III Freedom from Distractibility factor: its utility in identifying children with attention deficit hyperactivity disorder. Psychol Assess 1994;6:368-371.

55. Rosenthal EN, Riccio CA, Gsanger KM, Jarratt KP. Digit Span compo- 
nents as predictors of attention problems and executive functioning in children. Arch Clin Neuropsychol 2006;21:131-139.

56. Pasini A, Paloscia C, Alessandrelli R, Porfirio MC, Curatolo P. Attention and executive functions profile in drug naive ADHD subtypes. J Brain Dev 2007;29:400-408.

57. Min JW, Lee WH, Hong MH, Bahn GH. A pilot study of the usefulness of intelligence test in assessment of attention-deficit hyperactivity disorder. J Kor Acad Child Adolesc Psychiatry 2012;23:196-203.

58. Rowland AS, Skipper BJ, Umbach DM, Rabiner DL, Campbell RA, Naftel AJ, et al. The prevalence of ADHD in a population-based sample. J Attend Disord 2015;19:741-754.

59. Hong M, Kwack YS, Joung YS, Lee SI, Kim B, Sohn SH, et al. Nationwide rate of attention-deficit hyperactivity disorder diagnosis and phar- macotherapy in Korea in 2008-2011. Asia Pac Psychiatry 2014;6:379385.

60. Gimpel GA, Collett BR, Veeder MA, Gifford JA, Sneddon P, Bushman $\mathrm{B}$, et al. Effects of stimulant medication on cognitive performance of children with ADHD. Clin Pediatr 2005;44:405-411.

61. Advokat C, Martino L, Hill B, Gouvier W. Continuous Performance Test (CPT) of college students with ADHD, psychiatric disorders, cognitive deficits, or no diagnosis. J Atten Disord 2007;10:253-256.

62. Bhang SY, Kwack YS, Joung YS, Lee SI, Kim B, Sohn SH, et al. Factors that affect the adherence to ADHD medications during a treatment continuation period in children and adolescents: a nationwide retrospective cohort study using Korean Health Insurance data from 2007 to 2011. Psychiatry Investig 2017;14:158-165. 